\title{
Queer, sexualidade e movimento
}

\author{
Gustavo da Motta Silva' (iD 0000-0002-1874-3633 \\ 'Secretaria Municipal do Rio de Janeiro, Rio de Janeiro, RJ, Brasil. 22763-010 - \\ ciepsantos@rioeduca.net
}

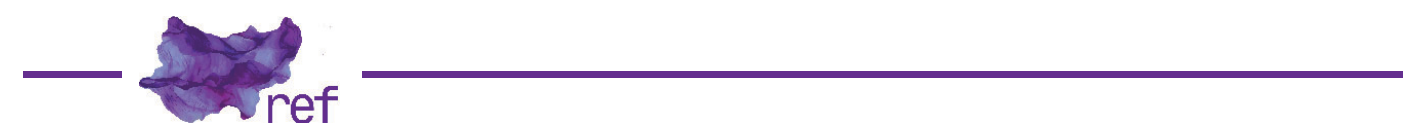

PEREIRA, Erik; SILVA, Alan (Orgs.).

Educação Física, Esporte e Queer: sexualidades em movimento.

Curitiba: Appris, 2019.

Educação Física, Esporte e Queer: sexualidades em movimento é uma coletânea organizada por dois professores de Educação Física com objetos de atuação/pesquisa complementares. Erik Giuseppe Barbosa Pereira é um autor que tem interesse na área da Educação Física na Educação Básica e as suas relações, representações e identidades de gênero. Já Alan Camargo Silva desenvolve estudos na perspectiva sociológica/antropológica e, dentre outros interesses de pesquisa, investiga homens, masculinidades e práticas corporais. $O$ prefácio é assinado pela professora Berenice Alves de Melo Bento, da Universidade de Brasília. No texto, a autora expressa o seu olhar a partir de suas áreas de interesse como decolonialidades, estudos queer, direitos humanos e marcadores sociais da diferença.

O livro apresenta um debate contextualizado e repleto de experiências no que diz respeito à educação física, ao esporte e ao queer. Tal como os organizadores destacam na apresentação, a publicação representa "uma iniciativa política e simbólica perante os referenciais binários, heteronormativos e androcêntricos que ainda atravessam as práticas corporais na contemporaneidade" (Erik PEREIRA; Alan SILVA, 2019, p. 9). Estruturalmente a obra foi organizada a partir de oito capítulos inseridos em quatro seções temáticas. Todas as seções englobam o potencial da analítica queer em diferentes âmbitos, objetos de estudo e relatos: "Experiência Queer", "Educação Física Queer, "Esporte Queer", "Esporte Queer na tela".

"Do céu ao inferno: relato de um corpo queer em uma corrida de rua", de Rafael Marques Garcia e Erik Giuseppe Barbosa Pereira, é o título correspondente ao único capítulo inserido na primeira seção. A partir da apresentação de relatos pessoais em consonância às inquietações relativas aos estudos queer, o capítulo projeta um relevante debate acerca de um corredor que usou short saia em uma corrida de rua no Rio de Janeiro. Ademais, destaca todos os olhares e (pré-)conceitos voltados para um homem trajando short saia. Dentre os vários sentimentos relatados, é pertinente destacar o de insegurança proporcionado pelas inúmeras ameaças de pessoas na rua. Sentimento esse que só passou quando o corredor chegou em casa e, em suas palavras, deu "um grito de sobrevivência" (Rafael GARCIA; Erik PEREIRA, 2019, p. 27).

O capítulo intitulado "Educação Física Escolar e o trato pedagógico com o esporte: proposições contrassexuais" integra a segunda seção. No estudo, as autoras Priscila Gomes Dornelles e lleana Wenetz procuraram desconstruir e debater a característica heteronormativa concernente à Escola enquanto instituição e à Educação Física como componente curricular. Defendem o esporte como conteúdo da Educação Física no âmbito educacional desde que contribuam para eliminar sistemas reprodutores de binarismos e de construções naturalizadas. 
O último capítulo dessa seção, "Corpos transgressores: contribuições da analítica queer para a área de Educação Física", é assinado por Alan Camargo Silva. Através de um olhar teórico aprofundado sobre o tema, o autor procura compreender os estudos queer enquanto campo de análise, contribuindo para desnormatizar e desregular os corpos normativamente lidos de forma natural. Com isso, o texto desenvolve uma discussão que busca associar/integrar o debate anteriormente descrito ao campo da Educação Física.

"Esporte Queer" é composto por dois capítulos. O primeiro, escrito por Leandro Teófilo de Brito e intitulado "Performances dissidentes no espaço do voleibol: masculinidades queer", apresenta e analisa os relatos de jovens atletas de voleibol, em clubes de base e colégios. O estudo identifica estereótipos, falas e preconceitos propiciados a partir de um discurso heteronormativo. Ainda que de modo hipotético, o autor busca designar uma forma de desheterossexualização do voleibol masculino.

Por sua vez, "A luta não pode parar: gênero sexualidade e a subversão corporal de atletas de esportes de combate", de Marco Antônio Carvalho Ferretti e Jorge Knijnik, tem como objetivo discutir a inserção e a presença de mulheres em esportes de combate. O trabalho é desenvolvido a partir dos relatos de cinco atletas com idade entre 21 e 32 anos de Modalidades Esportivas de Combate. De acordo com as ponderações dos autores, essas mulheres travam lutas dentro e fora dos ringues e tatames consentindo e resistindo com/aos olhares estereotipados de gênero e sexualidade. Segundo a fala das entrevistadas, o preconceito não está na visão de mulheres serem lutadoras, mas em mulheres (serem) masculinas (Marco FERRETTI; Jorge KNIJNIK, 2019). Entretanto, elas destacaram as aulas de Educação Física escolar como um momento de livre expressão, no qual poderiam romper barreiras de um corpo infantil, feminino e enclausurado pelas expectativas de gênero.

A última seção destaca os debates voltados para o esporte e o queer em filmes e documentários. Intitulado por "Corpos queer no esporte: uma leitura a partir de Game Face", o capítulo escrito por Paula Nunes Chaves investiga o documentário Game Face (dirigido por Michiel Thomas, lançado em 2015). O tema do documentário gira em torno da questão LGBT e queer no esporte através da narração da história de vida de duas atletas que rompem com os padrões de gênero e sexualidade. Como estratégia de análise, a autora reflete sobre o corpo e gênero a partir da ótica do queer compreendendo o gênero como uma expressão complexa ou fabricação de um corpo que possui várias maneiras de estar no mundo (Paula CHAVES, 2019).

No penúltimo capítulo, "Desejo, esporte e distinção: entre marcadores culturais e biológicos na representação de cartão vermelho", Allyson Carvalho de Araújo analisa a presença marginal da mulher no futebol a partir do curta-metragem brasileiro Cartão Vermelho (dirigido por Laís Bodanzky, lançado em 1994). O curta conta a história de uma adolescente de 12 anos e narra os seus sonhos, frustrações e preconceitos no mundo do futebol. Através da análise de algumas cenas, o autor busca identificar e compreender os marcadores culturais e biológicos existentes na realidade do futebol e da história apresentada.

O último capítulo da coletânea, "O Rural inesperado: diversidade e rupturas do mundo do rodeio", escrito por Miriam Adelman e Carla Bernava, almejou investigar os discursos de gênero e sexualidade no meio rural brasileiro e, de forma mais pontual, nos Estados Unidos, a partir do cinema. Ao analisar como a heteronormatividade e a homossocialidade estavam presentes no ponto de vista cultural e competitivo dos rodeios country as autoras identificaram códigos e identidades que reforçam cada vez esses discursos, além da sua propagação para os rituais do homem do campo e das atividades agropecuárias.

O conjunto de textos que integram o volume cumpre com o seu objetivo de ser uma iniciativa política e simbólica e, além disso, convida a refletir sobre os olhares que a sociedade continua a projetar sobre os corpos queer. Em um momento no qual, em diferentes partes do mundo, a diferença tem sido alvo de ataques violentos, uma obra com esse escopo nos demonstra a importância da luta por uma sociedade possa respeitar a diferença. A articulação entre os estudos queer e a Educação Física ainda é um campo pouco explorado e receberá mais atenção através da contribuição desta obra.

Por fim, vale pontuar que embora os textos presentes no livro tenham usando um referencial teórico específico e legitimado da área de gênero e sexualidade, a discussão apresentou, em alguns momentos, mais um discurso similar ao de outros capítulos do que propriamente uma efetiva articulação entre a teoria e o objeto analisado. Contudo, esse aspecto não compromete as contribuições das/os autoras/es, a originalidade das pesquisas e tampouco do livro.

Portanto, o livro trata os debates em torno do queer como algo que possa desestabilizar os conhecimentos do corpo e, além disso, reconhecer o seu potencial de análise. A obra apresenta uma importante contribuição para o campo dos estudos de gênero e sexualidade e aponta possibilidades efetivas para as análises da Educação Física e do esporte a partir dos estudos queer. 


\section{Referências}

CHAVES, Paula. "Corpos queer no esporte: uma leitura a partir de game face". In: PEREIRA, Erik; SILVA, Alan (Orgs.). Educação Física, Esporte e Queer: sexualidades em movimento. Curitiba: Appris, 2019, p. 129-151.

FERRETTI, Marco; KNIJNIK, Jorge. "A luta não pode parar: gênero, sexualidade e subversão cultural das atletas de esporte de combate". In: PEREIRA, Erik; SILVA, Alan (Orgs.). Educação Física, Esporte e Queer: sexualidades em movimento. Curitiba: Appris, 2019, p. 105-125.

GARCIA, Rafael; PEREIRA, Erik. "Do céu ao inferno: relato de um corpo queer em uma corrida de rua". In: PEREIRA, Erik; SILVA, Alan (Orgs.). Educação Física, Esporte e Queer: sexualidades em movimento. Curitiba: Appris, 2019, p. 19-35.

PEREIRA, Erik; SILVA, Alan. "Apresentação". In: PEREIRA, Erik; SILVA, Alan (Orgs.). Educação Física, Esporte e Queer: sexualidades em movimento. Curitiba: Appris, 2019, p. 9-11.

Gustavo da Motta Silva (gustavomotta1990@hotmail.com) é doutor em Educação pela Pontifícia Universidade Católica do Rio de Janeiro (PUC-Rio). Membro do Núcleo de Estudos Sociocorporais e Pedagógicos em Educação Física e Esportes (UFRJ/NESPEFE-EEFD) e do grupo de pesquisa História da Profissão Docente (PRODOC/PUC-Rio). Professor da Secretaria Municipal de Educação do Rio de Janeiro e da Secretaria Municipal de Educação de Duque de Caxias.

\section{COMO CITAR ESTE ARTICO DE ACORDO COM AS NORMAS DA REVISTA}

SILVA, Gustavo da Motta. "Queer, sexualidade e movimento". Revista Estudos Feministas, Florianópolis, v. 29, n. 2, e73490, 2021

\section{CONTRIBUIÇĀO DE AUTORIA}

Não se aplica.

\section{FINANCIAMENTO}

Não se aplica.

\section{CONSENTIMENTO DE USO DE IMAGEM}

Não se aplica.

\section{APROVAÇĀO DE COMITÊ DE ÉTICA EM PESQUISA}

Não se aplica.

\section{CONFLITO DE INTERESSES}

Não se aplica.

\section{LICENÇA DE USO}

Este artigo está licenciado sob a Licença Creative Commons CC-BY 4.0 International. Com essa licença você pode compartilhar, adaptar, criar para qualquer fim, desde que atribua a autoria da obra.

\section{HISTÓRICO}

Recebida em 02/05/2020

Revisões requeridas em 03/07/2020

Aprovada em 10/07/2020 